\title{
Psychological Status Monitoring with Cerebral Blood Flow, Electroencephalogram and Electro- oculogram Measurements
}

\author{
Kohei Arai \\ Graduate School of Science and Engineering, Saga University, Japan \\ E-mail: arai@is.saga.ac.jp
}

\begin{abstract}
Psychological status monitoring with Cerebral Blood Fflow: CBF, Electroencephalogram: EEG and Electrooculogram: EOG measurements are attempted. Through experiments, it is confirmed that the proposed method for psychological status monitoring is valid. It is also found correlations among the amplitudes of peak alpha and beta as well as gamma frequency of EEG signals and EOG as well as cerebral blood flow. Therefore, psychological status can be monitored with either EEG measurements or cerebral blood flow and EOG measurements.
\end{abstract}

Indeks Terms- Cerebral Blood Flow: CBF, Electroencephalogram: EEG And Electro-Oculogram: EOG, Psychological Status

\section{INTRODUCTION}

Psychological status monitoring is getting much important for health care. Eye based psychological status monitoring is proposed and applied to a variety of fields such as Electric Wheel Chair control, e-learning system, etc.[1]-[22].

The methods and measuring instruments are proposed and well developed now a day. Relations among the psychological status monitored with Cerebral Blood Flow: CBF, Electroencephalogram: EEG and Electrooculogram: EOG measurements are not clarified. In order to clarify the relations, experiments are conducted with patients through rhythm gaming and adding gaming. When the patients play rhythm game, in general, psychological statuses of the patients are calm and relax while psychological statuses of the patients are severe and irritated when they play adding game. Through the experiments, this paper intends to clarify the relations. Furthermore, appropriate monitoring method and system as well as measuring instruments for psychological status is clarified.

The paper is organized as follows. First, the method and procedure for psychological status monitoring is described followed by some experimental methods and procedures together with experimental results. Then some concluding remarks are described with some discussions.

\section{Method AND Procedure FOR Psychological STATUS MONITORING}

EEG and EOG sensors of ZA manufactured by ProAssist Co. Ltd. is used in experiments together with Near Infrared: NIR Spectroscopy (NIRS) of HOT 121-B manufactured by Hitachi Co. Ltd. for cerebral blood flow measurements. Table 1 and 2 show the major specifications of the EEG and EOG sensors of ZA and HOT 121-B of NIRS.

Table 1. Major Specification of EEG and EOG sensors of ZA

\begin{tabular}{|c|c|}
\hline Electrodes & EEG and EOG \\
\hline AD_converter & $12 \_$bit \\
\hline Sampling_Frequency & $128(\mathrm{kHz})$ \\
\hline Band_Width & Brain_Wave:0.5-40Hz\&Eye_Vol.:0.5-10Hz \\
\hline
\end{tabular}

Table 2. Major Specification of cerebral blood flow (CBF) Measuring Instrument HOT 121B

\begin{tabular}{|c|c|}
\hline Sampling & $100 \mathrm{~ms}$ \\
\hline Wave_Length & $810 \mathrm{~nm}$ \\
\hline Repetation_Cycle & $2 \mathrm{kHz}$ \\
\hline Temp.Sensor & $\pm 1^{\circ} \mathrm{C}$ \\
\hline Acceleration_Sensor & $\pm 2 \mathrm{G}$ \\
\hline EMI & VCC-1_ClassB \\
\hline Application & $\begin{array}{c}\text { Cerebral blood flow(left right), } \\
\text { heart rate, LF/HF, Attitude }\end{array}$ \\
\hline
\end{tabular}

In Table 2, LF/HF denotes the ratio of Sympathetic to Parasympathetic which is called heart rate changing index. Sympathetic is dominant when patients are in irritated, active and having stress status. Therefore, LF/HF is increased in such time period. On the other hand, LF/HF is decreased when patients are in relaxing, taking a rest, and sleeping status because parasympathetic is dominant in such time period.

The experiments are conducted with 5 patients. In the experiments, patient takes a rest for 1 minute and then plays for 1 minute with three games; adding game, rhythm game and breakout destroy game separately. It is suspected that most of patients are in relax status when they playing with rhythm game while are in irritating status when they plays with adding game and breakout destroy game. They have to have an instruction on how to 
play the games before getting start a set of experiment (1 minute for a rest and then 1 minute for gaming). They have to have 15 sets of experiment each. All sets of experiment are finished within a hour.

EEG data is filtered by low pass filter with cut off frequency of $50 \mathrm{~Hz}$ (6dB octave) for noise removals. After that FFT is applied to the filtered EEG. One of the examples is shown in Fig. 1.

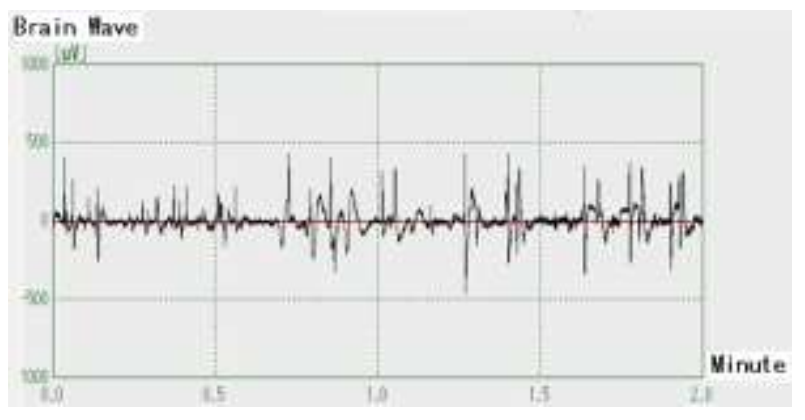

(a) Original EEG data

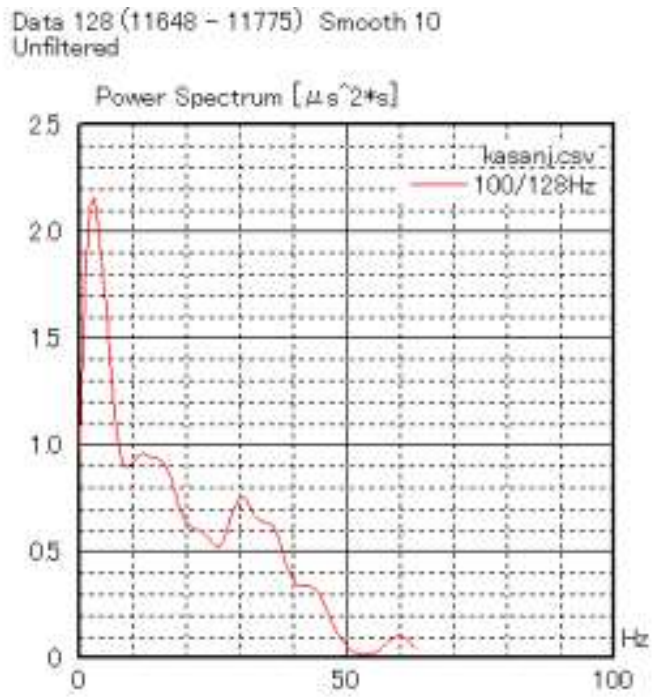

(b) Frequency component

Fig. 1. Examples of EEG and its frequency component
Usually, frequency components of 0-4 Hz, 4-8 Hz, 8$12 \mathrm{~Hz}, 12-40 \mathrm{~Hz}$ are named delta, theta, alpha and beta frequencies. In particular, alpha frequency component is dominant when users are in relaxing status while beta frequency component is large when they are in irritating status. When their EEG data is acquired, they have to attach electrodes on their forehead. This is the same thing for EOG measurements. They have to attach electrodes at the end of their eyes.

EOG data, on the other hand, show eye movement behavior which is reflected users' psychological status. Namely, EOG data is calm when they are in relaxing status while EOG data varied rapidly and quickly when they are in irritating status. Fig. 2 shows an example of EOG data. From the data, eye movement speed can be analyzed.

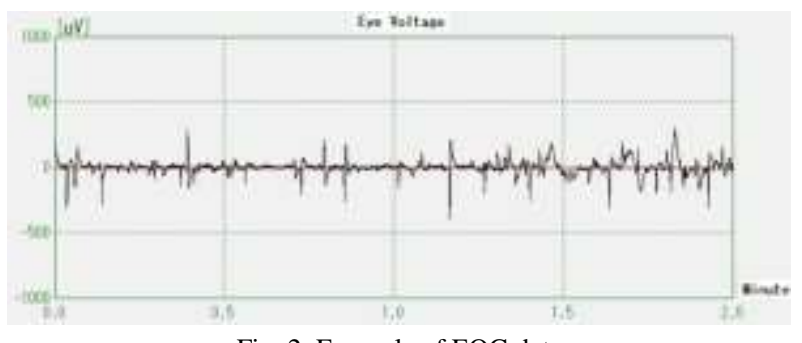

Fig. 2. Example of EOG data

Meanwhile, cerebral blood flow data shows varied rapidly and quickly when they are in irritating status while cerebral blood flow data shows calm when they are in relaxing status. It is expected that then they play with adding game, they are used to in an irritating status while they are in relaxing status when they play with rhythm game.

Fig. 3 shows an example of acquired cerebral blood flow data. There are two data of cerebral blood flows, left brain (Red colored line in Fig. 3) and right brain (Blue colored line in Fig. 3). Also, left and right heart rate is acquired with HOT 121-B sensor. In meantime, LF/HF of right brain and left brain are also measured.

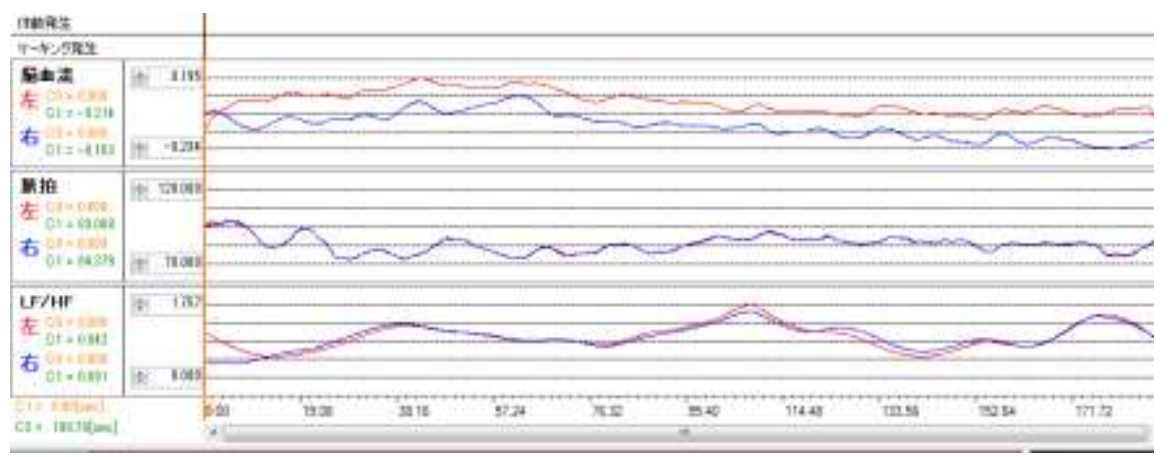

Fig. 3. shows an example of acquired cerebral blood flow data.

\section{EXPERIMENTAL RESULTS}

One of the typical measured data of cerebral blood flow, heart rate, $\mathrm{LF} / \mathrm{HF}$ of one of the patients is shown in Fig. 4 (a) together with EEG in Fig. 4 (b) and EOG in Fig. 4 (c). During the first half time, the patient takes a rest and plays rhythm game during the second half time period. As shown in Fig. 4, there is not so large difference of the measured data between the first and the second half time periods. Therefore, most of the patients are in relaxing status when they play rhythm game. 


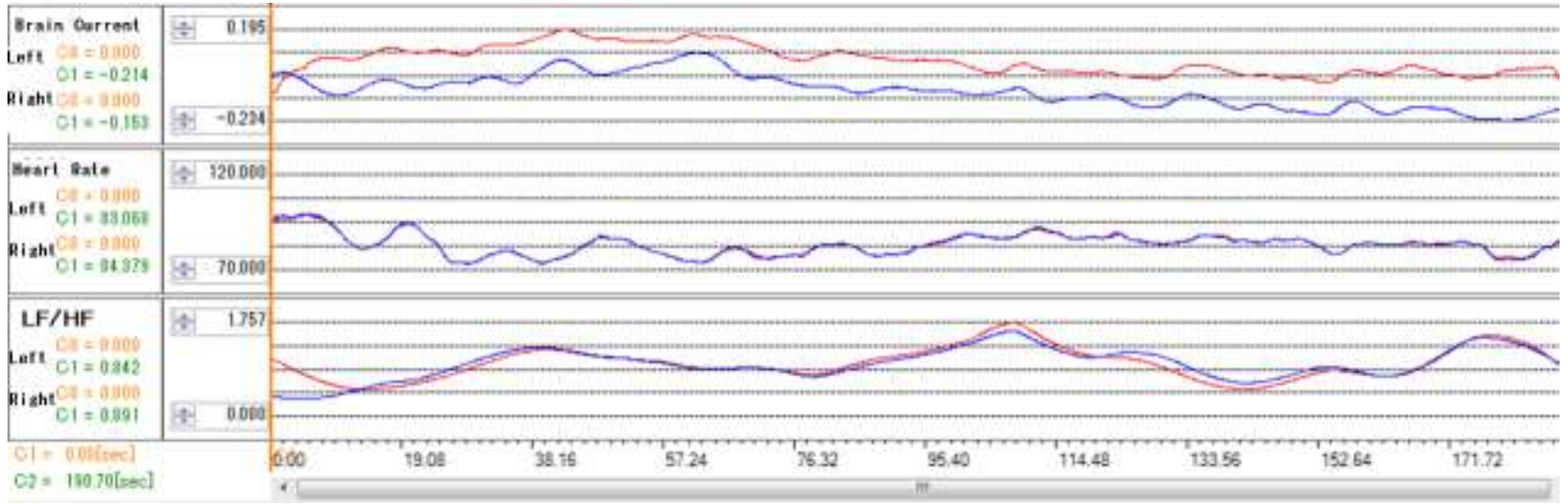

(a) Cerebral blood flow, Heart Rate, LF/HF

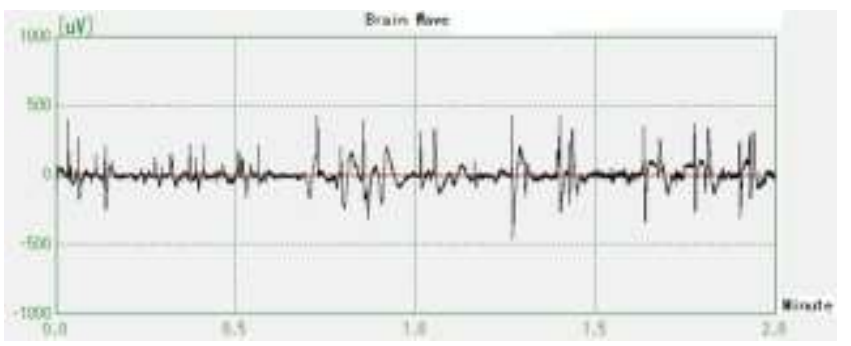

(b)EEG

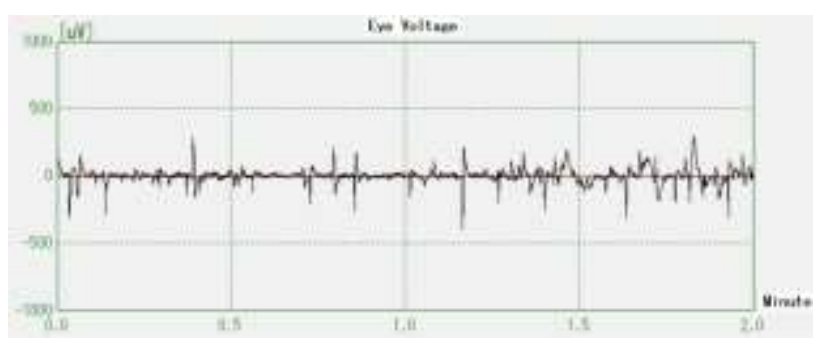

(c)EOG

Fig. 4. Measured data when the typical patient plays Rhythm Game

One of the typical measured data of cerebral blood flow, heart rate, $\mathrm{LF} / \mathrm{HF}$ of one of the patients is shown in Fig. 5 (a) together with EEG in Fig. 5 (b) and EOG in Fig. 5 (c). During the first half time, the patient takes a rest and plays adding game during the second half time period.
As shown in Fig. 5, there is relatively large difference of the measured data between the first and the second half time periods. Therefore, most of the patients are in irritating status when they play adding game.

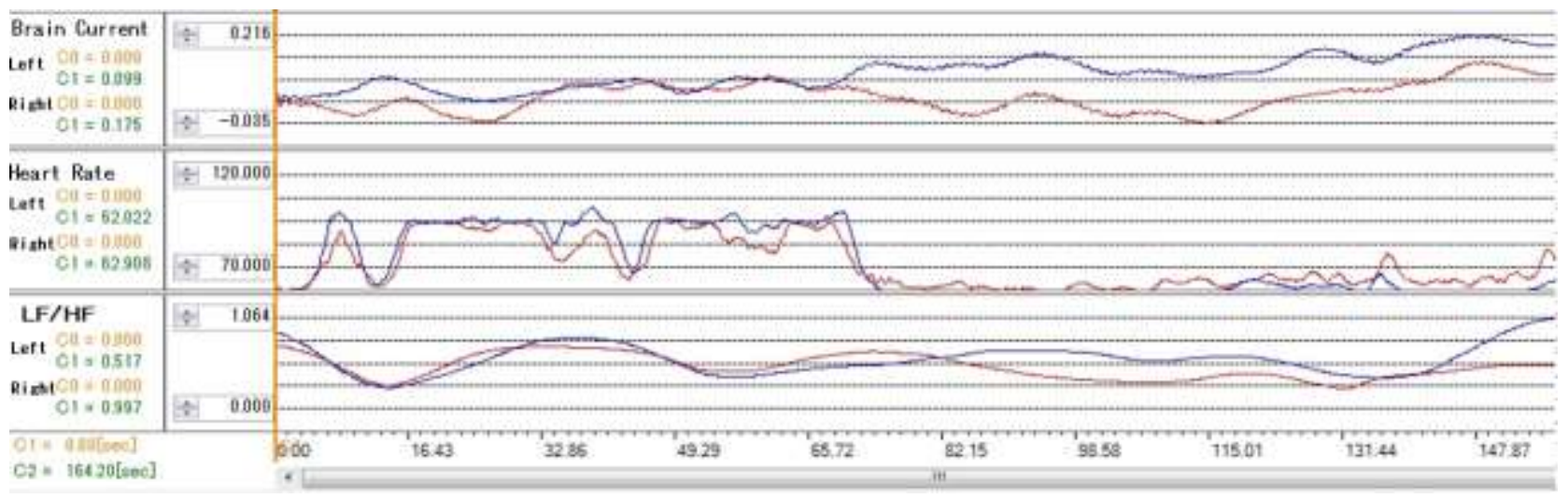

(a)Cerebral blood flow, Heart Rate, LF/HF

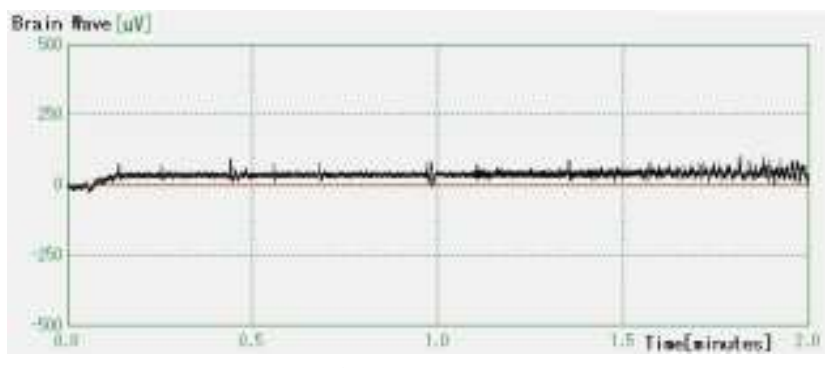

(b)EEG

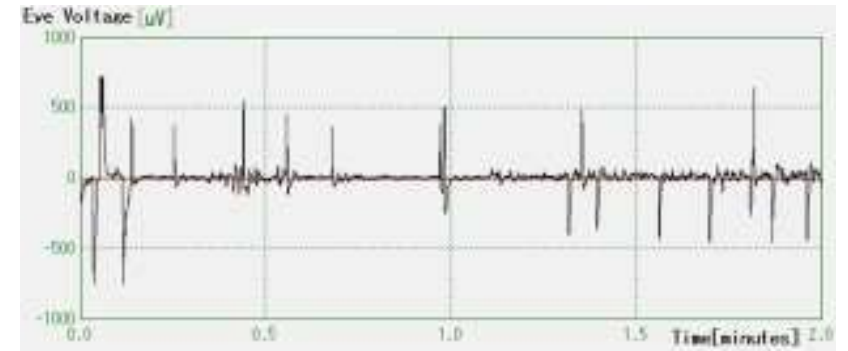

(c)EOG

Fig. 5. Measured data when the typical patient plays Adding Game

Meanwhile, frequency component of the measured EEGs when the patient plays rhythm game is shown in
Fig. 6 (a) while that for adding game is shown in Fig. 6 (b). 


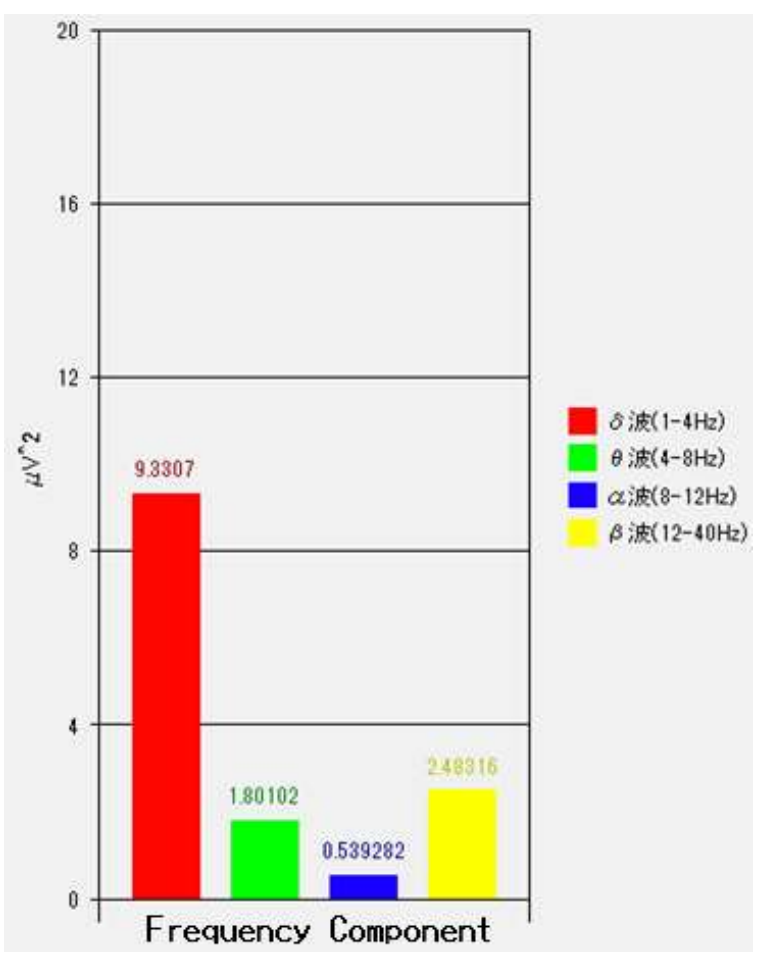

(a)Rhythm game

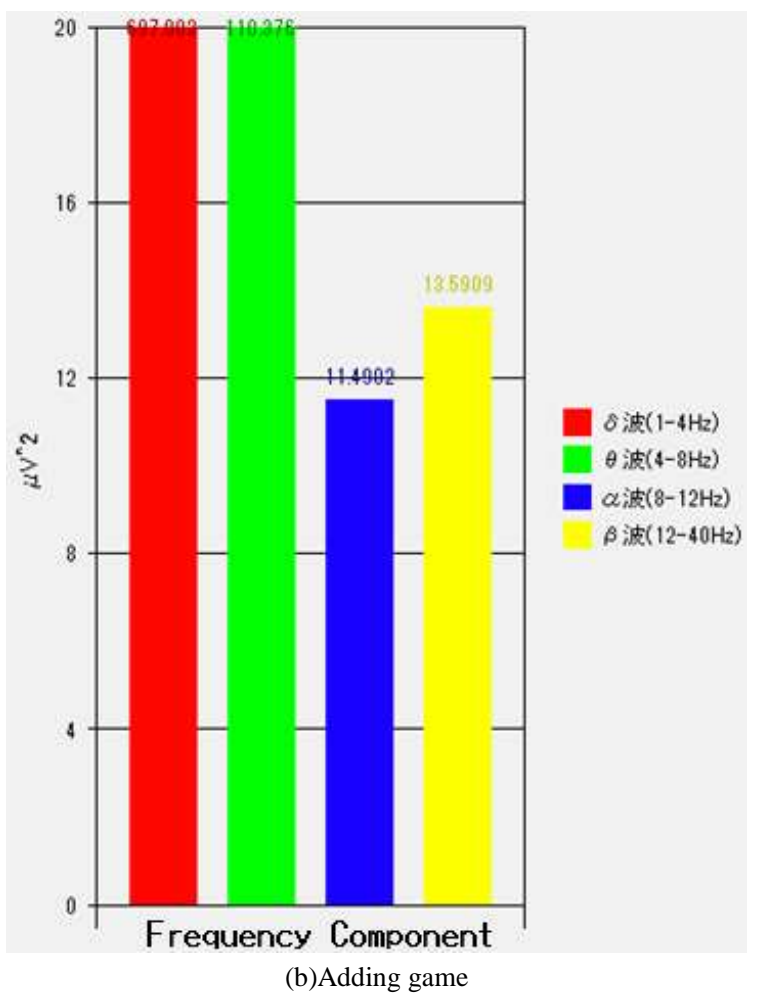

Fig. 6. Frequncy component of EEGs when the patient plays rhythm game and adding game

Table 3. Frequency components of the measured EEGs when the Patient

Plays Thythm Game and Adding Game
\begin{tabular}{|c|c|c|}
\hline Game & Rhythm & Adding \\
\hline$\delta$ & 697.003 & 9.3307 \\
\hline$\theta$ & 110.376 & 1.80102 \\
\hline$\alpha$ & 11.4002 & 0.53928 \\
\hline$\beta$ & 13.5909 & 2.48316 \\
\hline
\end{tabular}

As shown in Table 3, alpha wave is relatively small in comparison to beta wave when the patient palys adding game rather than rhythm game.

The amplitudes of peak alpha frequency, peak beta frequncy, as well as peak gamma frequency (more than $30 \mathrm{~Hz}$ ) are used to be evaluated as psychological status indexes. These are used to be highly correlated to cerebral blood flow, heart rate, and LF/HF. The amplitudes of peak beta frequency and peak gamma frequency together with EOG of the patient when he plays rhythm game are plotted in Fig. 7 (a), (b), and (c), respectively. EOG is highly correlated to the amplitudes of beta wave and gamma wave as shown in Fig. 8 . Correlation coefficients between EOG and beta wave amplitude is around 0.77 while that between EOG and gamma wave is 0.89 , respectively. Therefore, it implies that the patient is iiritated and stressed because his eyes move so rapidly and quickly.

On the other hand, the amplitudes of peak beta frequency and right cerebral blood flow of the patient when he plays rhythm game are plotted in Fig. 9 (a), and (b), respectively. Right cerebral blood flow is correlated to the amplitudes of beta wave as shown in Fig. 9 (c). Correlation coefficients between right cerebral blood flow and beta wave amplitude is around 0.45 .

Meanwhile, Fig. 10 (a) and (b) shows amplitudes of EEG of gamma frequency components and cerebral blood flow when the patient plays breakout game as well as correlations between cerebral blood flow and EEG of gamma frequency (Fig. 10 (c)). Correlation coefficients between right cerebral blood flow and beta wave amplitude of EEG is around 0.81 .

For the breakout game, in general, $\mathrm{CBF}$ is increased together with beta and gamma waves while EOG signal amplitude is relatively large. For the adding game, beta wave is increased while EOG signal amplitude is relatively small. On the other hand, $\mathrm{CBF}$ is decreased together with gamma wave while EOG signal amplitude is comparatively small for the rhythm game.

\section{Beta Wave Amplitude}

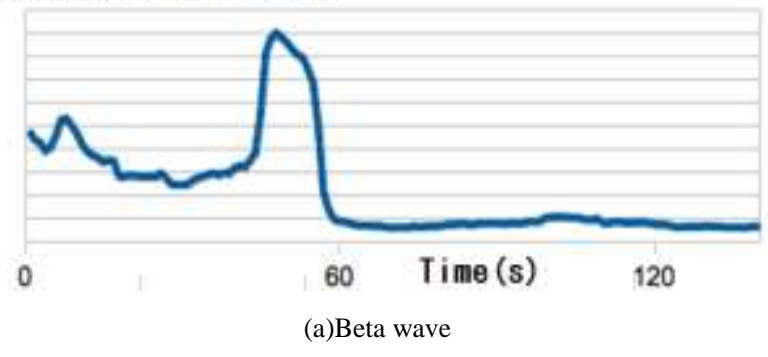

Gamma Wave 1 Amplitude

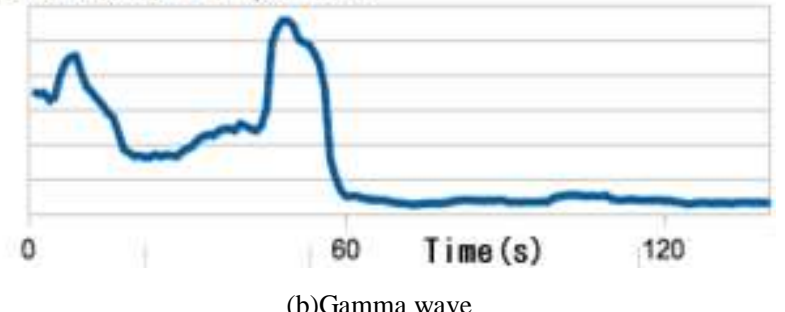

(b)Gamma wave 


\section{Eye Voltage Amplitude}

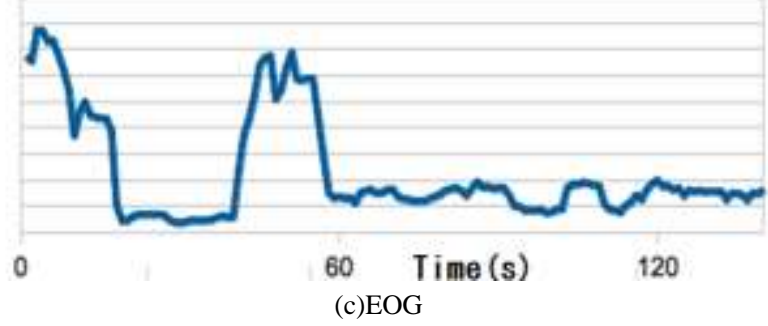

Fig. 7. Amplitudes of EEG of beta and gamma frequency components when the patient plays rhythm game

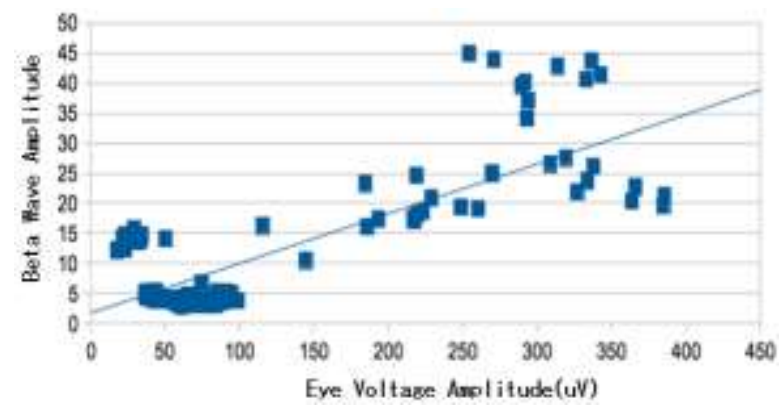

(a)Beta wave

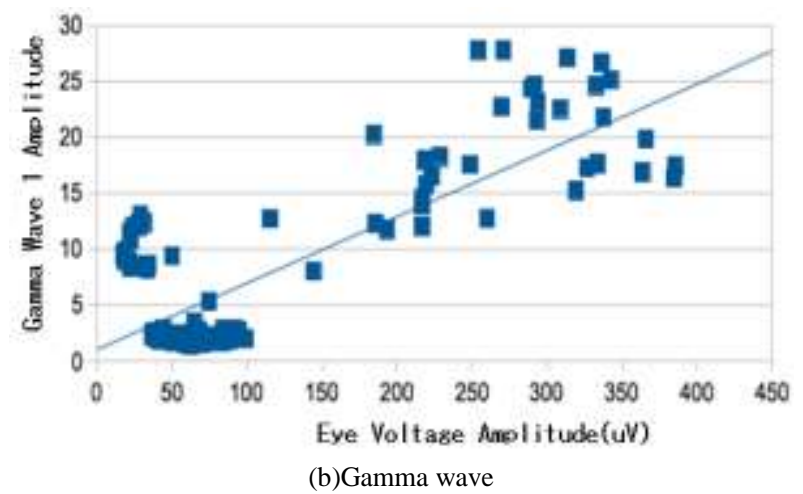

Fig. 8. Correlations between EOG and EEG of beta wave as well as gamma wave

\section{Right Brain Blood Current Amplitude}

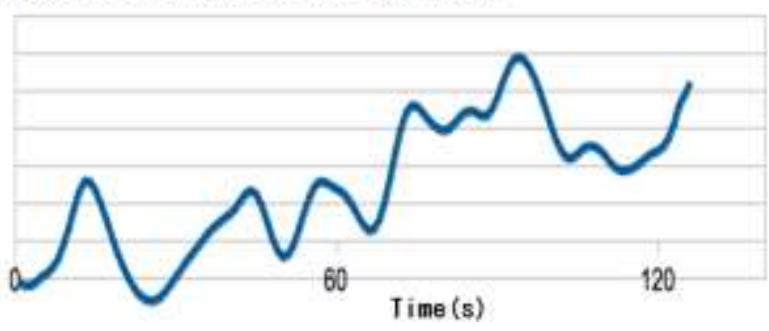

(a)Cerebral blood flow

Beta Wave Amp l itude

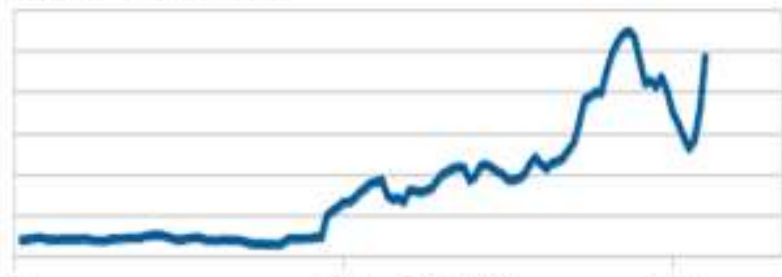

0

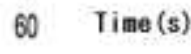

120

(b)Beta wave

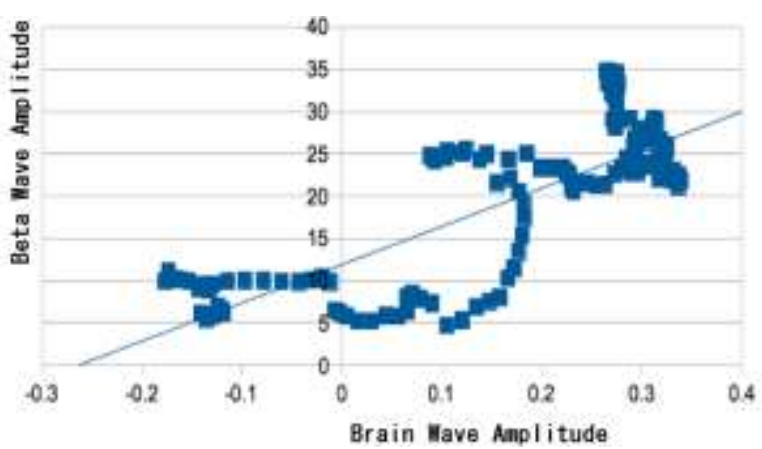

(c)Correlation

Fig. 9. Amplitudes of EEG of beta frequency components and cerebral blood flow when the patient plays adding game as well as correlations between cerebral blood flow and EEG of beta frequency

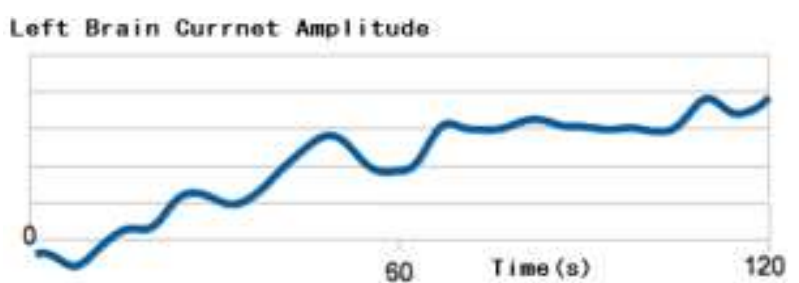

(a)Left CBF

Gamma Wave 1 Amplitude

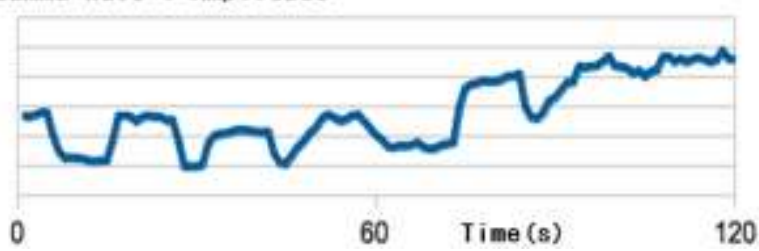

(b)Gamma wave

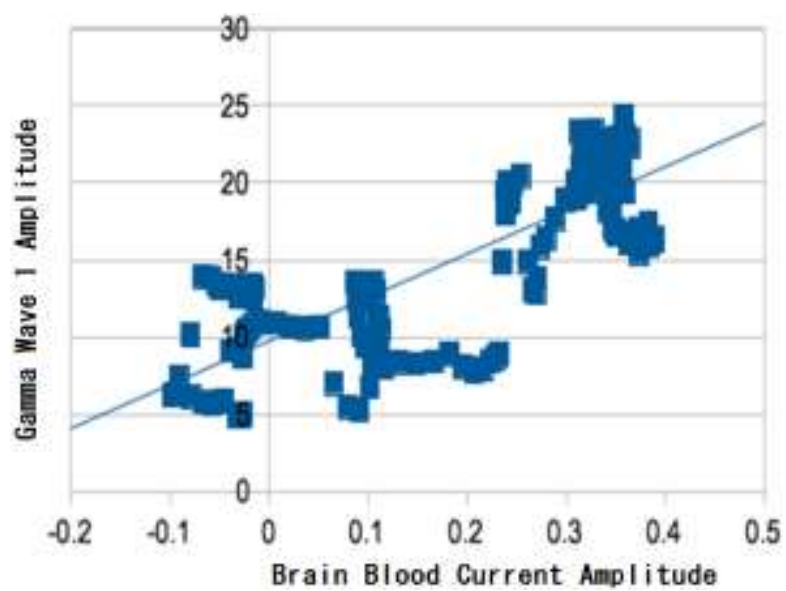

(c)Correlation between $\mathrm{CBF}$ and gamma wave of EEG

Fig. 10. Amplitudes of EEG of gamma frequency components and cerebral blood flow when the patient plays breakout game as well as correlations between cerebral blood flow and EEG of gamma frequency

As the experimental results, it is found that the followings,

(1) Breakout game:

1) three patients out of five patients show high correlations between $C B F$ and gamma wave of frequency component of EEG signals

2) two patients out of five patients show relatively high correlation between $C B F$ and beta wave of frequency component of EEG signals 
(2) Adding game:

1) Two patients out of five patients show comparatively high correlation between $C B F$ and beta wave of frequency component of EEG signals

(3) Rhythm game:

1) Three patients out of four patients show high correlation between EOG signal amplitude and beta/gamma frequency component of eeg signals

2) Two patients out of four patients show relatively high correlation between CBF and gamma wave of frequency component of EEG

\section{CONCLUSION}

Psychological status monitoring with cerebral blood flow (CBF), EEG (EEG) and EOG (EOG) measurements are attempted. Through experiments, it is confirmed that the proposed method for psychological status monitoring is valid. It is also found correlations among the amplitudes of peak alpha and beta EEGs and EOG as well as cerebral blood flow. Therefore, psychological status can be monitored with either EEG measurements or cerebral blood flow and EOG measurements.

It is found that three patients out of five patients show high correlations between $\mathrm{CBF}$ and gamma wave of frequency component of EEG signals for breakout game, two patients out of five patients show relatively high correlation between $\mathrm{CBF}$ and beta wave of frequency component of EEG signals for breakout game, two patients out of five patients show comparatively high correlation between $\mathrm{CBF}$ and beta wave of frequency component of EEG signals for adding game, three patients out of four patients show high correlation between EOG signal amplitude and beta/gamma frequency component of EEG signals for rhythm game, two patients out of four patients show relatively high correlation between $\mathrm{CBF}$ and gamma wave of frequency component of EEG for rhythm game.

From these experimental results, it may conclude that these EEG, EOG, and CBF are highly correlated. Therefore, these measurements can be used alternatively. $\mathrm{CBF}$ measuring instruments are relatively expensive than the others. EEG and EOG sensors are very sensitive to the surrounding noises rather than the others.

\section{REFERENCES}

[1] Djoko Purwanto, Ronny Mardiyanto and Kohei Arai, Electric wheel chair control with gaze detection and eye blinking, Artificial Life and Robotics, AROB Journal, 14, 694,397-400, 2009.

[2] Kohei Arai and Makoto Yamaura, Computer input with human eyes only using two Purkinje images which works in a real time basis without calibration, International Journal of Human Computer Interaction, 1,3, 71-82,2010

[3] Kohei Arai, Ronny Mardiyanto, A prototype of electric wheel chair control by eye only for paralyzed user, Journal of Robotics and Mechatronics, 23, 1, 66-75, 2010.

[4] Djoko Purwanto, Ronny Mardiyanto, Kohei Arai, Electric wheel chair control with gaze detection and eye blinking,
Proceedings of the International Symposium on Artificial Life and Robotics, GS9-4, 2009.

[5] Kohei Arai and Kenro Yajima, Communication Aid and Computer Input System with Human Eyes Only, Electronics and Communications in Japan, Volume 93, Number 12, 2010, pages 1-9, John Wiley and Sons, Inc., 2010.

[6] Kohei Arai, Ronny Mardiyanto, Evaluation of users' impact for using the proposed eye based HCI with moving and fixed keyboard by using eeg signals, International Journal of Research and Reviews on Computer Science, 2, 6, 1228-1234, 2011.

[7] Kohei Arai, Kenro Yajima, Robot arm utilized having meal support system based on computer input by human eyes only, International Journal of Human-Computer Interaction, 2, 1, 120-128, 2011.

[8] Kohei Arai, Ronny Mardiyanto, Autonomous control of eye based electric wheel chair with obstacle avoidance and shortest path finding based on Dijkstra algorithm, International Journal of Advanced Computer Science and Applications, 2, 12, 19-25, 2011.

[9] Kohei Arai, Ronny Mardiyanto, Eye-based humancomputer interaction allowing phoning, reading e-book/ecomic/e-learning, Internet browsing and TV information extraction, International Journal of Advanced Computer Science and Applications, 2, 12, 26-32, 2011.

[10] Kohei Arai, Ronny Mardiyanto, Eye based electric wheel chair control system-I(eye) can control EWC-, International Journal of Advanced Computer Science and Applications, 2, 12, 98-105, 2011.

[11] Kohei Arai, Ronny Mardiyanto, Electric wheel chair controlled by human eyes only with obstacle avoidance, International Journal of Research and Reviews on Computer Science, 2, 6, 1235-1242, 2011.

[12] Kohei Arai, Ronny Mardiyanto, Evaluation of users' impact for using the proposed eye based HCI with moving and fixed keyboard by using eeg signals, International Journal of Research and Reviews on Computer Science, 2, 6, 1228-1234, 2011.

[13] K.Arai, R.Mardiyanto, Evaluation of users' impact for using the proposed eye based HCI with moving and fixed keyboard by using eeg signals, International Journal of Research and review on Computer Science, 2, 6, 12281234, 2012.

[14] K.Arai, R.Mardiyanto, Electric wheel chair controlled by human eyes only with obstacle avoidance, International Journal of Research and review on Computer Science, 2, 6, 1235-1242, 2012.

[15] R.Mardiyanto, K.Arai, Eye-based Human Computer Interaction (HCI) A new keyboard for improving accuracy and minimizing fatigue effect, Scientific Journal Kursor, (ISSN 0216-0544), 6, 3, 1-4, 2012.

[16] K.Arai, R.Mardiyanto, Moving keyboard for eye-based Human Computer Interaction: HCI, Journal of Image and Electronics Society of Japan, 41, 4, 398-405, 2012.

[17] Kohei Arai, Ronny Mardiyanto, Eye-based domestic robot allowing patient to be self-services and communications remotely, International Journal of Advanced Research in Artificial Intelligence, 2, 2, 29-33, 2013.

[18] Kohei Arai, Ronny Mardiaynto, Method for psychological status estimation by gaze location monitoring using eyebased Human-Computer Interaction, International Journal of Advanced Computer Science and Applications, 4, 3, 199-206, 2013.

[19] Kohei Arai, Kiyoshi Hasegawa, Method for psychological status monitoring with line of sight vector changes (Human eyes movements) detected with wearing glass, 
Electro-oculogram Measurements

International Journal of Advanced Research in Artificial Intelligence, 2, 6, 65-70, 2013.

[20] Kohei Arai, Wearable computing system with input output devices based on eye-based Human Computer Interaction: HCI allowing location based web services, International Journal of Advanced Research in Artificial Intelligence, 2, 8, 34-39, 2013.

[21] Kohei Arai Ronny Mardiyanto, Speed and vibration performance as well as obstacle avoidance performance of electric wheel chair controlled by human eyes only, International Journal of Advanced Research in Artificial Intelligence, 3, 1, 8-15, 2014.

[22] Kohei Arai Ronny Mardiyanto, Speed and vibration performance as well as obstacle avoidance performance of electric wheel chair controlled by human eyes only, International Journal of Advanced Research in Artificial Intelligence, 3, 1, 8-15, 2014.

\section{Author's Profile}

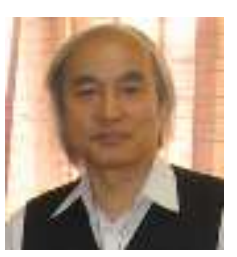

Kohei Arai received $\mathrm{BS}$, MS and $\mathrm{PhD}$ degrees in 1972, 1974 and 1982, respectively. He was with The Institute for Industrial Science and Technology of the University of Tokyo from April 1974 to December 1978 and also was with National Space Development Agency of Japan from January, 1979 to March, 1990. During from 1985 to 1987, he was with Canada Centre for Remote Sensing as a Post Doctoral Fellow of National Science and Engineering Research Council of Canada. He moved to Saga University as a Professor in Department of Information Science on April 1990. He was a councilor for the Aeronautics and Space related to the Technology Committee of the Ministry of Science and Technology during from 1998 to 2000. He was a councilor of Saga University for 2002 and 2003. He also was an executive councilor for the Remote Sensing Society of Japan for 2003 to 2005. He is an Adjunct Professor of University of Arizona, USA since 1998. He also is Vice Chairman of the Commission A of ICSU/COSPAR since 2008. He wrote 33 books and published 500 journal papers.

How to cite this paper: Kohei Arai,"Psychological Status Monitoring with Cerebral Blood Flow, Electroencephalogram and Electro-oculogram Measurements", International Journal of Information Technology and Computer Science(IJITCS), vol.7, no.8, pp.1-7, 2015. DOI: 10.5815/ijitcs.2015.08.01 